\title{
Effects of Tiotropium Combined with Theophylline on Stable COPD Patients of Group B, D and its Impact on Small Airway Function: A Randomized Controlled Trial
}

Xiao-feng Xiong · Li-li Fan · Hong-xia Wu • Min Zhu •

De-yun Cheng

Received: September 12, 2018 / Published online: November 10, 2018

(C) The Author(s) 2018

\section{ABSTRACT}

Introduction: Tiotropium bromide has been widely used in clinical practice, while theophylline is another treatment option for chronic obstructive pulmonary disease (COPD). However, only a few relevant studies have investigated the long-term outcomes and efficacy of both in patients with COPD. We evaluated the effects of tiotropium and low-dose theophylline on stable COPD patients of groups $B$ and D.

Methods: Eligible participants $(n=170)$ were randomized and received either tiotropium $18 \mu \mathrm{g}$ once daily with theophylline $100 \mathrm{mg}$ twice daily (Group I) or tiotropium $18 \mu$ g once daily (Group II) for 6 months. COPD assessment

Enhanced digital features To view enhanced digital features for this article go to https://doi.org/10.6084/ m9.figshare.7257275.

Electronic supplementary material The online version of this article (https://doi.org/10.1007/s12325018-0831-9) contains supplementary material, which is available to authorized users.

X. Xiong · L. Fan · H. Wu · M. Zhu · D. Cheng ( $₫)$ Department of Respiratory and Critical Care Medicine, West China Hospital of Sichuan

University, Chengdu, Sichuan, China

e-mail: chengdeyunscu@163.com test (CAT), modified Medical Research Council (mMRC) dyspnea scores and pulmonary function tests were measured before randomization and during the treatment.

Results: After 6 months of treatment, the CAT scores in both groups decreased significantly $(11.41 \pm 3.56$ and $11.08 \pm 3.05, p<0.0001)$. The changes of CAT $(p=0.028)$ and mMRC scores $(p=0.049)$ between the two groups differed after 1 month of treatment. In Group I, forced expiratory flow after $25 \%$ of the $\mathrm{FVC} \%$ predicted $\left(\mathrm{MEF}_{25} \%\right.$ pred $)$ was significantly improved after 3 months $(4.84 \pm 8.73 \%$, $p<0.0001)$ and 6 months $(6.21 \pm 8.65 \%$, $p<0.0001)$. There was a significant difference in small airway function tests $\left(\mathrm{MEF}_{50} \%\right.$ pred, $\mathrm{MEF}_{25} \%$ pred, and $\mathrm{MMEF} \%$ pred) between the two groups after 6 month of treatment $(p=0.003, \quad p<0.0001, \quad$ and $p=0.021$, respectively).

Conclusions: Tiotropium combined with lowdose theophylline significantly improved the symptoms and general health of patients with stable COPD of groups B and D after 6 months of follow-up. Additionally, this therapy also improved the indicators of small airway function.

Trial Registration: Chinese Clinical Trial Registry (Registry ID: ChiCTR1800019027).

Keywords: COPD; Small airway; Stable stage; Tiotropium; Theophylline 


\section{INTRODUCTION}

Chronic obstructive pulmonary disease (COPD) is a common, preventable, and treatable disease that is characterized by persistent respiratory symptoms and airflow limitation [1], and its morbidity and mortality rates are on the rise. Globally, the COPD burden is projected to increase in the future owing to the continued exposure to COPD risk factors and population aging [2]. Other important factors contributing to the burden are patients' lack of knowledge of COPD, their denial of pulmonary function testing and reasonable standard treatments, and poor patient compliance to prescribed medications in the stable period. Therefore, the treatment of COPD, especially the management of stable COPD, is particularly important.

In 2011, the global initiative for chronic obstructive lung disease (GOLD) guidelines proposed that stable COPD patients should be divided into four groups (A, B, C, and D) according to the clinical symptoms and risk of future acute exacerbation [3]. The symptom scores of patients in groups $\mathrm{B}$ and $\mathrm{D}$ were higher than those in groups $\mathrm{A}$ and $\mathrm{C}$, which indicates that the former COPD group patients have more prominent respiratory symptoms, such as chronic cough, sputum production and dyspnea. Moreover, several studies have suggested that the proportion of COPD patients in groups $\mathrm{B}$ and $\mathrm{D}$ are higher than in groups A and C [4-7]. The GOLD 2017 guidelines recommend long-acting anticholinergic agents (LAMAs) as the preferred treatment in different groups of stable COPD [1]. Previous studies have shown that inhaled tiotropium relieves symptoms and improves the pulmonary function and quality of life [8-10]. There have been numerous reports on the use of tiotropium in COPD patients in China, but few are randomized controlled clinical trials with a large sample size.

Oral slow-release theophylline is widely used as a bronchodilator. Kanehara et al. found low-dose theophylline not only improved forced vital capacity (FVC), forced expiratory volume in $1 \mathrm{~s}$ $\left(\mathrm{FEV}_{1}\right)$, and forced expiratory volume in $1 \mathrm{~s} \%$ predicted ( $\mathrm{FEV}_{1} \%$ pred), but also improved the small airway function [11]. However, Berger and Smith, showed that theophylline could not improve the small airway function [12]. Because of the differences noted by the aforementioned studies, the effects of low-dose theophylline on the small airway function in patients with stable COPD remain controversial. In addition, limited research has been performed using the combination of tiotropium bromide and theophylline in China and abroad. Thus, the efficacy of this combination needs to be further clinically evaluated.

Therefore, we conducted a prospective randomized controlled trial to investigate the effects of tiotropium alone and tiotropium combined with low-dose theophylline in patients with stable COPD of groups B and D.

\section{METHODS}

The study was performed at the West China Hospital of Sichuan University. The protocol was designed in accordance with good clinical practice and the latest revisions to the Declaration of Helsinki. The study was approved by the institutional ethics committees of the West China Hospital of Sichuan University, and it has been registered at http://www.chictr.org.cn/ (ChiCTR1800019027). All participants gave informed consent, and all work was conducted in accordance with the Declaration of Helsinki (1964).

\section{Patients}

Outpatients with a clinical diagnosis of stable COPD were recruited from March 2015 to June 2016 in the West China Hospital of Sichuan University, China. The inclusion criteria were as follows: confirmed COPD of groups B and $\mathrm{D}$ by pulmonary physicians based on the 2015 GOLD guidelines [13], age $\geq 40$ years, aand bsence of exacerbations [13] for at least 1 month. Exclusion criteria: patients used LAMAs, long-acting $\beta_{2}$-adrenergic agonists (LABAs), inhaled glucocorticoids, oral or intravenous glucocorticoid in the previous 1 month, with any infection in the previous 1 month before study entry, with proved prostatic hyperplasia, bladder neck stenosis or narrow angle glaucoma, or with other clinically significant lung diseases (e.g., asthma, bronchiectasis, 
cancer or tuberculosis). We used group design mean comparison to estimate sample size, and the calculation formula was $n=2\left(Z_{\alpha}+Z_{\beta}\right)^{2} \sigma^{2} / \delta^{2}$, $Z_{\alpha / 2}=1.96, \quad Z_{\beta}=0.842, \quad \sigma=3.08, \quad \delta=\pi_{2}-\pi_{1}=$ 1.45; each group needed 56 cases, a total of 142 cases in the two groups, plus $20 \%$ of the withdrawal cases (about $142 \times 0.2=28$ cases), and the total estimated sample size was 170 patients.

\section{Study Design}

We conducted a 6-month, randomized, controlled, parallel-group open-label trial. Eligible participants were then randomly assigned (1:1) using a computer-generated randomization list to one of two arms: Group I: tiotropium $18 \mu \mathrm{g}$ once daily by Handihaler (Boehringer Ingelheim Pharma, Ingelheim, Germany) plus slow-release theophylline $100 \mathrm{mg}$ twice daily by oral (Maite Xing Hua Pharmaceutical Factory, Guangzhou, China) group; Group II: tiotropium $18 \mu \mathrm{g}$ oncedaily group. None of the patients was treated with oral prednisolone, LABAs, antihistamines, antileukotrienes, or cromolyn throughout the study.

The treatment duration was 6 months, with clinical visits at the end of the first month (visit 2 ), the third month (visit 3) and the sixth month (visit 4). During the treatment, subjects with any of the following conditions were removed from the study: combined with acute exacerbations; poor compliance (taking $<80 \%$ or $>120 \%$ of the dosage); occurring serious adverse events; combined with any one of the above exclusion criteria.

\section{Pulmonary Function Test}

The spirometry was performed before and after inhalation of a bronchodilator. We recorded the following indicators: $\mathrm{FVC}, \mathrm{FEV}_{1}, \mathrm{FEV}_{1} \%$ pred, $\mathrm{FEV}_{1} / \mathrm{FVC}$, peak expiratory flow $\%$ predicted (PEF\% pred), forced expiratory flow after $75 \%$ of the $\mathrm{FVC} \%$ predicted $\left(\mathrm{MEF}_{75} \%\right.$ pred), $\mathrm{MEF}_{50} \%$ pred, $\mathrm{MEF}_{25} \%$ pred, maximal mid-expiratory flow\% predicted (MMEF\% pred). PEF\% pred and $\mathrm{MEF}_{75} \%$ pred are the indicators of airflow in large airways; $\mathrm{MEF}_{50} \%$ pred, $\mathrm{MEF}_{25} \%$ pred, and $\mathrm{MMEF} \%$ pred are the indicators of airflow in small airways.

\section{Outcome Measurements}

The primary outcomes included COPD assessment test (CAT) score, the modified British Medical Research Council (mMRC) dyspnea scale score and pulmonary function test indicators at baseline and each visit. According to COPD-related minimal clinically important differences, lung function of $\mathrm{FEV}_{1}$ should increase $100 \mathrm{ml}$, while modified Medical Research Council (mMRC) dyspnea scores should decrease 1 unit [14]. The secondary outcomes were acute exacerbations and adverse events.

\section{Statistical Analysis}

All statistical analysis was performed using SPSS 20.0 (IBM, Chicago, IL, USA), and a $p$ value $<0.05$ was considered statistically significant. Means and standard derivations (SD) are used for those variables with normal distributions. Other variables are expressed as medians and inter-quartile ranges. Dichotomous variables (COPD exacerbations, complications, adverse events) were reported as frequencies and proportions.

The demographic data, clinical data, and outcome indexes were compared between the two groups at baseline and each visit. For variables with normal distribution, we used the independent sample $t$ test, while for non-normal data, we used the independent samples Mann-Whitney $U$ test. When comparing the symptom scores and lung function of the two arms between baseline and each visit, we used the paired sample $t$ test if the data had normal distribution, otherwise we used the Wilcoxon signed-rank test. The Chi squared test was used to compare the rates of complications and adverse events of the two groups.

\section{RESULTS}

\section{Subjects}

Patients were enrolled between March 2015 and June 2016. A total of 170 subjects underwent randomization, 164 subjects (96.5\%) completed 
the first visit after 1 month of treatment, 155 subjects $(91.2 \%)$ completed the second visit after 3 months of treatment, finally, 142 subjects $(83.5 \%)$ completed the third visit after 6 months of treatment. The enrollment and outcomes are shown in Fig. 1. Baseline characteristics of the two groups were similar (Table 1).

\section{CAT and mMRC Score}

CAT and mMRC scores of two groups decreased significantly after treatment (Tables 2,3 ). After 1 month of treatment, the mean decreases of CAT and mMRC scores in Group I was more prominent than in Group II $(p=0.028$ and $p=0.049$, respectively), while,this effect was not observed after 3 months and 6 months of treatment (Fig. 2; Table 4).

\section{Pulmonary Function}

In Group I, the median baseline FVC level was $2.38 \mathrm{~L}$, the median FVC levels of subjects who completed the second, third and fourth visit were $2.51 \mathrm{~L}, 2.54 \mathrm{~L}$ (compared with baseline, $p<0.05$ ) and $2.63 \mathrm{~L}$ (compared with baseline, $p<0.001)$, respectively; the median baseline $\mathrm{FEV}_{1}$ level was $1.19 \mathrm{~L}$. The median $\mathrm{FEV}_{1}$ levels of subjects who completed the second, third and fourth visit were $1.28 \mathrm{~L}, 1.32 \mathrm{~L}$ (compared with baseline, $p<0.05$ ) and $1.36 \mathrm{~L}$ (compared with baseline, $p<0.05$ ), respectively (Table 2 ). In Group II, the median baseline FVC level was 2.31 L. The median FVC levels of subjects who completed the second, third and fourth visit were $2.36 \mathrm{~L}, 2.44 \mathrm{~L}$ (compared with baseline, $p<0.05$ ) and $2.48 \mathrm{~L}$ (compared with baseline, $p<0.05)$, respectively; the median baseline $\mathrm{FEV}_{1}$ level was $1.19 \mathrm{~L}$, the median $\mathrm{FEV}_{1}$ levels of subjects who completed the second, third and fourth visit were $1.24 \mathrm{~L}, 1.29 \mathrm{~L}$ (compared with baseline, $p<0.001$ ) and $1.31 \mathrm{~L}$ (compared with baseline, $p<0.05$ ), respectively (Table 3 ). Similarly, the other pulmonary function indicators $\left(\mathrm{FEV}_{1} \%\right.$ pred, $\mathrm{FEV}_{1} / \mathrm{FVC}$, PEF\% pred, $\mathrm{MEF}_{75} \%$ pred, $\mathrm{MEF}_{50} \%$ pred) increased significantly in both groups (compared with baseline, $p<0.05$ ) after 3 months and 6 months of treatment (Tables 2, 3).
The small airway function $\left(\mathrm{MEF}_{25} \%\right.$ pred and MMEF\% pred) increased in Group I (compared with baseline, $p<0.05$ ) after 3 -month and 6-month treatment, while, this effect was not observed in Group II (Tables 2, 3). After 1 month of treatment, $\mathrm{MEF}_{50 \%}, \mathrm{MEF}_{25} \%$ pred and MMEF\% pred level in Group I changed by a mean (SD) of $3.28 \pm 8.70 \%, 3.81 \pm 9.71 \%$ and $1.84 \pm 8.50 \%$, respectively, none of which with statistical difference compared with Group II. After 3-month treatment, $\mathrm{MEF}_{50} \%, \mathrm{MEF}_{25} \%$ pred and MMEF\% pred level in Group I changed by a mean (SD) of $4.38 \pm 8.57 \%, 4.84 \pm 8.73 \%$ and $2.70 \pm 8.65 \%$, respectively, $\mathrm{MEF}_{25} \%$ pred showed statistical difference compared with Group II $(p=0.004)$. After 6 months of treatment, $\mathrm{MEF}_{50} \%, \mathrm{MEF}_{25} \%$ pred and $\mathrm{MMEF} \%$ pred level in Group I changed by a mean (SD) of $5.77 \pm 8.79 \%, 6.21 \pm 8.65 \%$ and $3.64 \pm 9.20 \%$, respectively, all of which had statistical difference compared with Group II (Fig. 2).

\section{Adverse Events}

Adverse events in each group are summarized in Table 5. Four and five serious adverse events were observed in the combination therapy group and the tiotropium-alone group, respectively. In addition to the one patient who was hospitalized for spinal surgery in the combination therapy group and one patient who was hospitalized due to acute appendicitis in the tiotropium-alone group, the rest of hospitalizations were due to acute exacerbations of COPD. No recruited subjects had vicious events associated with adverse events, and no deaths occurred.

\section{DISCUSSION}

Our study was a prospective randomized controlled trial. We innovatively selected patients with groups B and D COPD with severe symptoms as research participants. We used LAMA, which is recommended by GOLD 2017 for each group of stable COPD patients, as the control therapy. This is the first study to explore the effect of low-dose theophylline combined with tiotropium bromide on small airway function in 


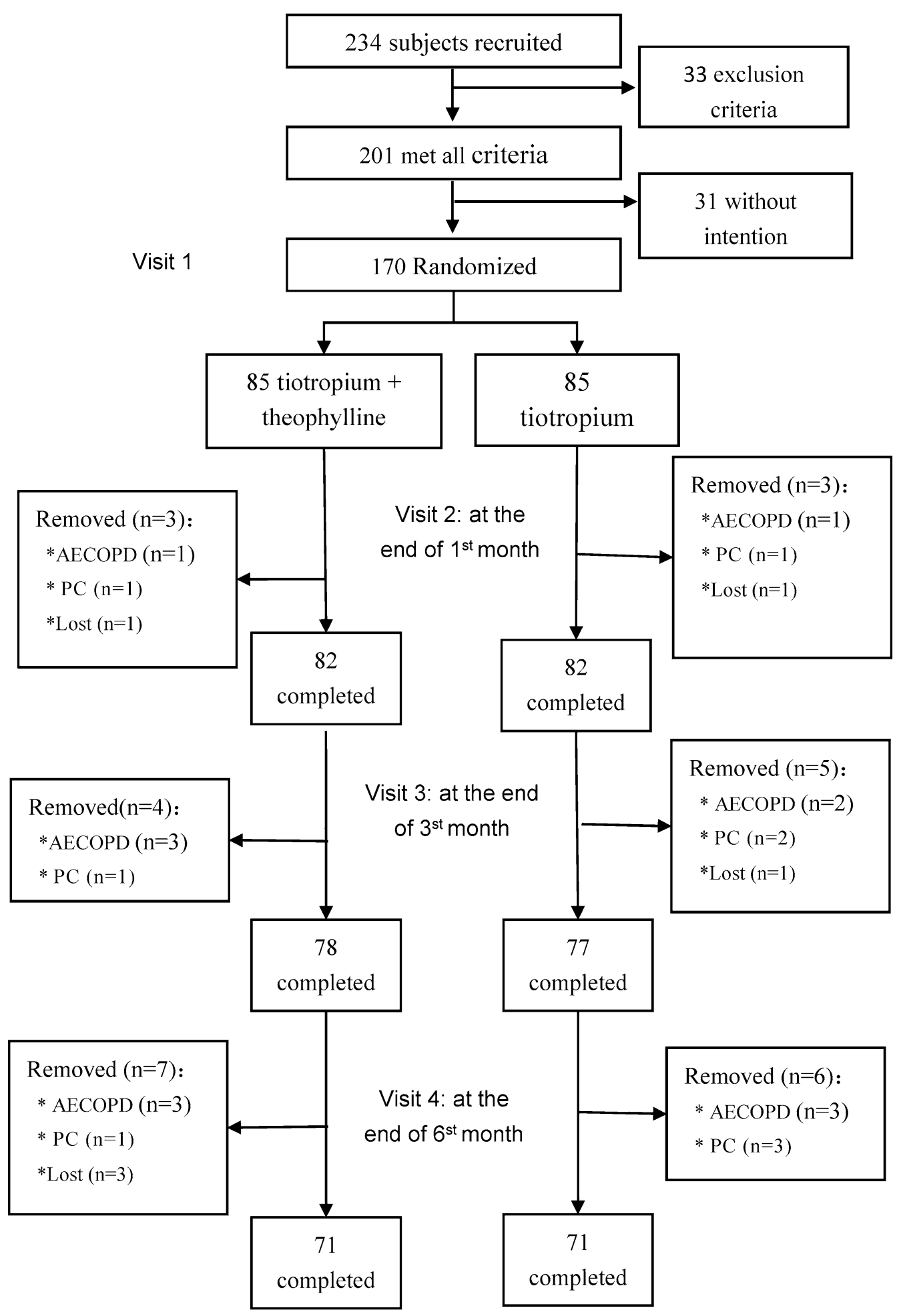

Fig. 1 Enrollment and outcomes. $A E C O P D$ acute exacerbation of chronic obstructive pulmonary disease, $P C$ poor compliance 
Table 1 Demographic and clinical characteristics of patients with COPD at baseline

\begin{tabular}{|c|c|c|c|}
\hline & Group I & Group II & $p$ value \\
\hline$n$ & 85 & 85 & \\
\hline Age, years & $62.27 \pm 8.03$ & $64.52 \pm 8.22$ & 0.140 \\
\hline Male, $n(\%)$ & $70(82.3)$ & $68(80.0)$ & 0.854 \\
\hline BMI, $\mathrm{kg} / \mathrm{m}^{2}$ & $22 \pm 3.01$ & $22.4 \pm 3.86$ & 0.439 \\
\hline Smoking status, $n(\%)$ & & & 0.710 \\
\hline Never & $17(20.0)$ & $20(23.5)$ & \\
\hline Current & $27(31.8)$ & $21(24.7)$ & \\
\hline Previous & $41(48.2)$ & $44(51.8)$ & \\
\hline Pack-years smoked ${ }^{a}$ & $40.5(11.5-45)$ & $35(15-50)$ & 0.193 \\
\hline GOLD stage, $n(\%)$ & & & 0.914 \\
\hline GOLD 1 & $3(4)$ & $4(5)$ & \\
\hline GOLD 2 & $25(29)$ & $33(39)$ & \\
\hline GOLD 3 & $47(55)$ & $25(29)$ & \\
\hline GOLD 4 & $10(12)$ & $23(27)$ & \\
\hline Cor pulmonale, $n(\%)$ & $18(21)$ & $19(22)$ & 0.853 \\
\hline Home oxygen therapy, $n$ (\%) & $6(7)$ & $5(6)$ & 0.883 \\
\hline Exacerbation history ${ }^{a}$ & $2(1-2)$ & $1(1-2)$ & 0.552 \\
\hline CAT score & $20.89 \pm 4.25$ & $22.19 \pm 4.47$ & 0.055 \\
\hline mMRC dyspnoea score, $n(\%)$ & & & 0.409 \\
\hline 0 & 0 & 0 & \\
\hline 1 & $1(1.2)$ & $0(0)$ & \\
\hline 2 & $35(41.2)$ & $32(37.6)$ & \\
\hline 3 & $47(55.3)$ & $49(57.6)$ & \\
\hline 4 & $2(2.3)$ & $4(4.8)$ & \\
\hline $\mathrm{FVC}(\mathrm{L})$ & $2.38 \pm 0.82$ & $2.31 \pm 0.76$ & 0.547 \\
\hline $\mathrm{FEV}_{1}(\mathrm{~L})$ & $1.19 \pm 0.52$ & $1.19 \pm 0.5$ & 0.315 \\
\hline $\mathrm{FEV}_{1} \%$ pred & $46.55 \pm 15.94$ & $46.56 \pm 18.98$ & 0.999 \\
\hline $\mathrm{FEV}_{1} / \mathrm{FVC}(\%)$ & $49.98 \pm 9.59$ & $48.61 \pm 12.2$ & 0.415 \\
\hline PEF\% pred & $40.47 \pm 18.85$ & $39.24 \pm 19.16$ & 0.672 \\
\hline $\mathrm{MEF}_{75} \%$ pred & $21.9 \pm 12.46$ & $23.02 \pm 16.35$ & 0.615 \\
\hline $\mathrm{MEF}_{50} \%$ pred & $17.35 \pm 10.25$ & $17.58 \pm 12.84$ & 0.898 \\
\hline $\mathrm{MEF}_{25} \%$ pred & $19.1 \pm 11.58$ & $20.04 \pm 11.87$ & 0.599 \\
\hline MMEF\% pred & $17.11 \pm 9.13$ & $18.16 \pm 12.36$ & 0.528 \\
\hline
\end{tabular}


Table 1 continued

\begin{tabular}{llll}
\hline & Group I & Group II & $\boldsymbol{p}$ value \\
\hline Complications, $n(\%)$ & & & 0.832 \\
Cardiovascular disease & $11(12.9)$ & $12(14.1)$ & 0.509 \\
Hypertension & $10(11.8)$ & $14(16.5)$ & 0.621 \\
Diabetes & $3(3.5)$ & $1(1.2)$ & 180 \\
\hline
\end{tabular}

Group I: tiotropium $18 \mu \mathrm{g}$ once-daily + theophylline $100 \mathrm{mg}$ twice-daily groups, Group II: tiotropium $18 \mu \mathrm{g}$ once-daily group

Data presented as mean (SD) unless specified

$B M I$ body mass index, GOLD global Initiative for Chronic Obstructive Lung Disease, $C A T$ COPD assessment test, $m M R C$ modified Medical Research Council, $F V C$ forced vital capacity, $F E V_{1}$ forced expiratory volume in one second, $F E V_{1} \% p r e d$ forced expiratory volume in one second $\%$ predicted, $P E F \%$ pred peak expiratory flow $\%$ predicted, $M E F_{75} \%$ pred forced expiratory flow after $75 \%$ of the FVC\% predicted, $M E F_{50} \%$ pred forced expiratory flow after $50 \%$ of the FVC $\%$ predicted, $M E F_{25} \%$ pred Forced expiratory flow after $25 \%$ of the FVC\% predicted, $M M E F \%$ pred maximal mid expiratory flow\% predicted

${ }^{\text {a }}$ Mean (range). Pack-years smoked, packs of cigarette per day $\times$ smoking years

patients with COPD. We demonstrated that add-on therapy with low-dose theophylline significantly improved the symptom scores and pulmonary function, especially small airway function in patients with stable COPD of groups $\mathrm{B}$ and $\mathrm{D}$ who are already on tiotropium treatment.

Previous studies have shown that inhaled tiotropium relieves symptoms and improves the pulmonary function and quality of life in COPD patients $[8,15,16]$. The 1-year Prevention of Exacerbations with Tiotropium in COPD (POETCOPD) trial [17] showed that tiotropium was more effective than salmeterol in preventing exacerbations in 7376 patients with moderateto-very-severe COPD. A meta-analysis comparing the relative clinical effects of tiotropium and LABAs revealed that, although both were similar in symptom improvement and changes in lung function, tiotropium was more effective than LABAs as a group in preventing COPD exacerbations and disease-related hospitalizations [18]. Recently, Suissa et al. showed that COPD treatment initiation with tiotropium compared with LABAs does not increase cardiovascular risk in the first year of treatment [19]. The above studies tend to show that tiotropium is superior to LABAs; therefore, we chose tiotropium as the control therapy.
The 1-month short-term follow-up results showed that the CAT scores and mMRC dyspnea scores decreased significantly in both groups, suggesting that both combination therapy and tiotropium alone could improve the symptoms of COPD patients. We also found that the changes of CAT and mMRC scores between the two groups after treatment were significant. It is suggested that the combined treatment could alleviate the symptoms of COPD patients in a short time, which is consistent with the results of several studies. A randomized controlled study conducted by Kawayama et al. compared effects of tiotropium combined with theophylline versus theophylline alone on lung function (including $\mathrm{FVC}, \mathrm{FEV}_{1}$, and PEF) and mMRC scores in stable COPD patients; the combination treatment was superior to the latter in all respects [20].

A previous study showed that therapy with tiotropium improved the absolute value of FVC and $\mathrm{FEV}_{1}$ during a 4 -year follow-up period in patients with COPD [8]. Our results indicated that the combination of low-dose theophylline and tiotropium could not improve the lung function in stable COPD patients in the short term, but improved the absolute values of FVC and $\mathrm{FEV}_{1}$ in the long term. Kohansal et al. 
Table 2 Changes in symptom scores and lung function of subjects in Group I during 6 months of therapy

\begin{tabular}{|c|c|c|c|c|}
\hline & Visit 1 & Visit 2 & Visit 3 & Visit 4 \\
\hline$n$ & 85 & 82 & 78 & 71 \\
\hline CAT score & $20.89 \pm 4.25$ & $15.38 \pm 3.01^{* *}$ & $12.34 \pm 2.87^{* *}$ & $9.39 \pm 2.43^{* *}$ \\
\hline mMRC score ${ }^{a}$ & & ** & $* *$ & $* *$ \\
\hline FVC (L) & $2.38 \pm 0.82$ & $2.51 \pm 0.79$ & $2.54 \pm 0.79^{*}$ & $2.63 \pm 0.91^{* *}$ \\
\hline $\mathrm{FEV}_{1}(\mathrm{~L})$ & $1.19 \pm 0.52$ & $1.28 \pm 0.57$ & $1.32 \pm 0.59^{*}$ & $1.36 \pm 0.59^{*}$ \\
\hline $\mathrm{FEV}_{1} \%$ pred & $46.55 \pm 15.94$ & $48.67 \pm 17.91$ & $50.90 \pm 18.03^{*}$ & $51.92 \pm 18.40^{* *}$ \\
\hline $\mathrm{FEV}_{1} / \mathrm{FVC}(\%)$ & $49.98 \pm 9.59$ & $50.87 \pm 11.09$ & $51.45 \pm 10.77^{* *}$ & $52.12 \pm 11.14^{*}$ \\
\hline PEF\% pred & $40.47 \pm 18.85$ & $46.67 \pm 19.75^{* *}$ & $46.76 \pm 18.66^{* *}$ & $47.07 \pm 19.54^{* *}$ \\
\hline $\mathrm{MEF}_{75} \%$ pred & $21.9 \pm 12.46$ & $25.85 \pm 18.36^{*}$ & $27.12 \pm 17.89^{* *}$ & $28.52 \pm 18.46^{* *}$ \\
\hline $\mathrm{MEF}_{50} \%$ pred & $17.35 \pm 10.25$ & $20.90 \pm 13.76^{*}$ & $21.89 \pm 14.23^{* *}$ & $23.32 \pm 14.40^{* *}$ \\
\hline $\mathrm{MEF}_{25} \%$ pred & $19.1 \pm 11.58$ & $23.12 \pm 15.13^{*}$ & $24.25 \pm 14.33^{* *}$ & $25.50 \pm 14.27^{* *}$ \\
\hline MMEF\% pred & $17.11 \pm 9.13$ & $19.1 \pm 11.49$ & $19.93 \pm 11.99^{*}$ & $20.86 \pm 12.50^{* *}$ \\
\hline
\end{tabular}

Group I: tiotropium $18 \mu \mathrm{g}$ once-daily + theophylline $100 \mathrm{mg}$ twice-daily group; Visit 1 : at the beginning of therapy; Visit 2: at the end of 1 month- of herapy; Visit 3: at the end of 3 months of therapy; Visit 4: at the end of 6 months of therapy Data presented as mean $(\mathrm{SD})$ unless specified

$C A T$ COPD assessment test, $F V C$ forced vital capacity, $F E V_{1}$ forced expiratory volume in one second, $F E V_{1} \%$ pred forced expiratory volume in one second\% predicted, $P E F \%$ pred peak expiratory flow\% predicted, $M E F_{75} \%$ pred forced expiratory flow after $75 \%$ of the $\mathrm{FVC} \%$ predicted, $M E F_{50 \%}$ pred forced expiratory flow after $50 \%$ of the FVC\% predicted, $M E F_{25 \%}$ pred forced expiratory flow after $25 \%$ of the FVC\% predicted, MMEF\% pred maximal mid expiratory flow\% predicted

${ }^{a}$ mMRAC index belongs to grade data, and was analyzed by Wilcoxon signed-rank test

${ }^{*}$ Compared to baseline, $p<0.05$

${ }^{* *}$ Compared to baseline, $p<0.001$

found that high airway mucus secretion is related to the $\mathrm{FEV}_{1}$ decline [21]. Therefore, we have a reason to believe that tiotropium improves $\mathrm{FEV}_{1}$ by antagonizing the cholinergic receptor and reducing airway mucus secretion. Compared with tiotropium monotherapy, adding theophylline (200 mg twice daily) did not improve FVC and $\mathrm{FEV}_{1}$ in patients with stable COPD. This was different from Cazzola and Matera's findings, which may be related to several factors [23]. First, their study added formoterol on tiotropium. Second, the follow-up period of 8 weeks was short, while our follow-up was for 6 months. Third, the sample size was small (36 cases). Therefore, further clinical research is required to investigate whether adding oral low-dose theophylline on tiotropium can improve lung function.
Pathological changes characteristic of COPD is found in the airways, lung parenchyma, and pulmonary vasculature [22]. Small airway dysfunction in COPD patients is significant. Our study showed that oral low-dose theophylline added on tiotropium could not significantly improve the small airway function in COPD patients in the short term, but it could alleviate the patient's small airway flow limitation in the long term. Our results were consistent with an 8 -week randomized controlled study that showed low-dose theophylline significantly improved lung function in patients with stable COPD [11]. Theophylline can dilate both the central airways and peripheral small airways. A previous study has shown that oral theophylline can reduce gas trapping in COPD patients, which suggests its impact on the 
Table 3 Changes in symptom scores and lung function of subjects in Group II during 6 months of therapy

\begin{tabular}{lllll}
\hline & Visit 1 & Visit 2 & Visit 3 & Visit 4 \\
\hline$n$ & 85 & 82 & 78 & 71 \\
CAT score & $22.19 \pm 4.47$ & $17.51 \pm 3.74^{* *}$ & $13.97 \pm 3.72^{* *}$ & $10.37 \pm 3.10^{* *}$ \\
mMRC score & $* *$ & $* *$ & $* *$ \\
FVC (L) & $2.31 \pm 0.76$ & $2.36 \pm 0.55$ & $2.44 \pm 0.56^{*}$ & $2.48 \pm 0.55^{*}$ \\
FEV $_{1}(\mathrm{~L})$ & $1.19 \pm 0.5$ & $1.24 \pm 0.49$ & $1.29 \pm 0.47^{* *}$ & $1.31 \pm 0.47^{*}$ \\
$\mathrm{FEV}_{1 \%}$ pred & $46.56 \pm 18.98$ & $50.27 \pm 19.51^{* *}$ & $51.47 \pm 19.92^{* *}$ & $53.30 \pm 19.43^{*}$ \\
$\mathrm{FEV}_{1} / \mathrm{FVC}(\%)$ & $48.61 \pm 12.2$ & $50.71 \pm 12.86^{*}$ & $51.03 \pm 12.15^{*}$ & $52.01 \pm 11.81^{*}$ \\
$\mathrm{PEF} \%$ pred $^{*}$ & $39.24 \pm 19.16$ & $43.74 \pm 18.90^{* *}$ & $44.86 \pm 19.19^{* *}$ & $46.51 \pm 19.14^{*}$ \\
$\mathrm{MEF}_{75 \%}$ pred & $23.02 \pm 16.35$ & $26.23 \pm 17.73^{*}$ & $26.61 \pm 18.06^{*}$ & $27.17 \pm 17.45$ \\
$\mathrm{MEF}_{50 \%}$ pred & $17.58 \pm 12.84$ & $19.76 \pm 13.82^{*}$ & $19.94 \pm 12.95^{*}$ & $20.56 \pm 12.42^{*}$ \\
$\mathrm{MEF}_{25 \%}$ pred & $20.04 \pm 11.87$ & $22.09 \pm 13.17$ & $21.80 \pm 10.85$ & $22.65 \pm 11.51$ \\
$\mathrm{MMEF} \%$ pred & $18.16 \pm 12.36$ & $19.57 \pm 12.93$ & $19.72 \pm 12.66$ & $20.04 \pm 12.50$ \\
\hline
\end{tabular}

Group I: tiotropium $18 \mu \mathrm{g}$ once-daily + theophylline $100 \mathrm{mg}$ twice-daily groups; Visit 1: at the beginning of therapy; Visit 2: at the end of 1 month of herapy; Visit 3: at the end of 3 months of therapy; Visit 4: at the end of 6 months of therapy $C A T$ COPD assessment test, $F V C$ forced vital capacity, $F E V_{1}$ forced expiratory volume in one second, $F E V_{1 \%}$ pred forced expiratory volume in one second\% predicted, $P E F \%$ pred peak expiratory flow\% predicted, $M E F_{75 \%}$ pred forced expiratory flow after $75 \%$ of the $\mathrm{FVC} \%$ predicted, $M E F_{50 \%}$ pred forced expiratory flow after $50 \%$ of the FVC\% predicted, $M E F_{25 \%}$ pred forced expiratory flow after $25 \%$ of the FVC\% predicted, $M M E F \%$ pred maximal mid expiratory flow $\%$ predicted Data presented as mean $(\mathrm{SD})$ unless specified

a mMRAC index belongs to grade data, and was analyzed by Wilcoxon signed-rank test

${ }^{*}$ Compared to baseline $p<0.05$

${ }^{* *}$ Compared to baseline, $p<0.001$

peripheral airways [23]. Recent studies have shown that low-dose theophylline (150-$300 \mathrm{mg} /$ day) has an airway anti-inflammatory effect, it inhibits oxidative stress, and regulates immunity [24-27]. Therefore, the mechanism of low-dose theophylline in improving small airway function may be related to its ability to control airway inflammation and relieve airway smooth muscle spasm; however, the specific mechanism remains to be further researched.

The common adverse effects of tiotropium are dry mouth, COPD exacerbation, and respiratory tract infection [28]. The main adverse reactions to oral theophylline are gastrointestinal discomfort, tachycardia, and nervous system symptoms [11], and patients present with nausea, palpitations, and headaches. Our study showed low-dose theophylline combined with tiotropium was relatively safe in the treatment of patients with stable COPD of groups B and D.

Our study had several limitations. First, we did not have a placebo control group. This is because the selected subjects were stable COPD of groups B and D with severe symptoms and (or) poor lung function; it was not possible to ethically have a placebo control group. Second, the study was an open-label experiment without blinding due to technical conditions and therefore prone to bias. Third, the relationship between therapies and the reduction in COPD exacerbations was not analyzed due to the limitation of follow-up time. Fourth, some subjects had poor compliance, changed treatment themselves and adjusted the drug doses, which resulted in the observations not being comprehensive. 
A Changes of CAT scores during 6 months of therapy

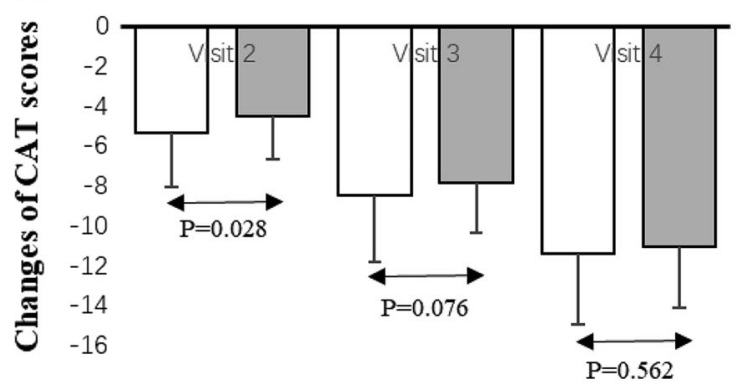

口Group | aGroup ||

C Changes of $M_{E F} \%$ pred during 6 months of therapy

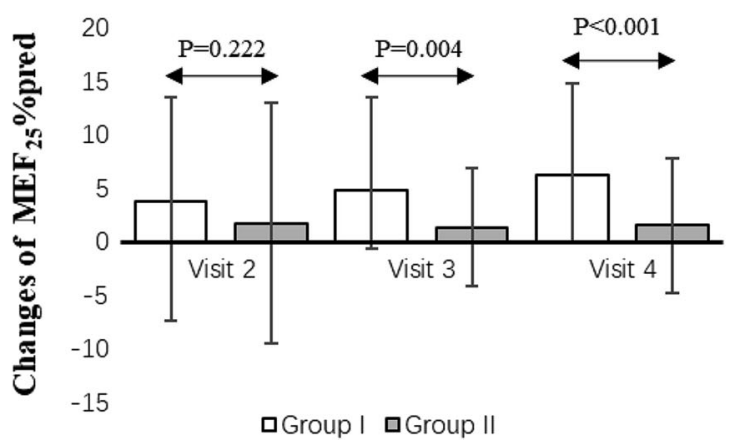

Fig. 2 Treatment differences in terms of a CAT, b $\mathrm{MEF}_{50} \%$ pred, $\mathbf{c} \mathrm{MEF}_{25} \%$ pred, $\mathbf{d} \mathrm{MMEF} \%$ pred during 6 months of therapy. Group I: tiotropium $18 \mu \mathrm{g}$ oncedaily + theophylline $100 \mathrm{mg}$ twice-daily groups, Group II: tiotropium $18 \mu \mathrm{g}$ once-daily group; Visit 2: at the end of 1 month of therapy; Visit 3: at the end of 3 months of

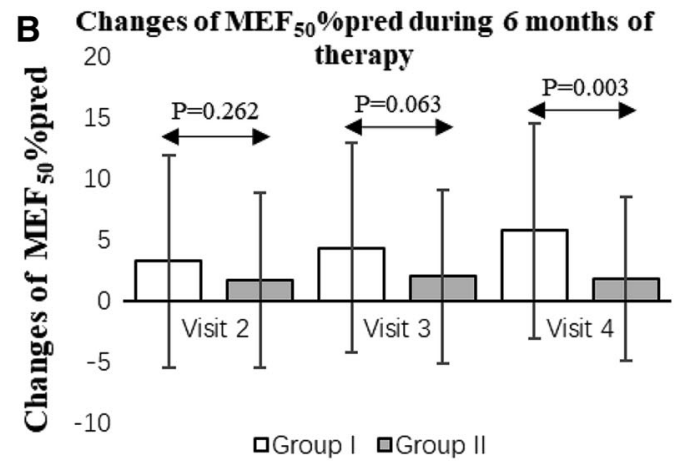

D Changes of MMEF\%pred during 6 months of

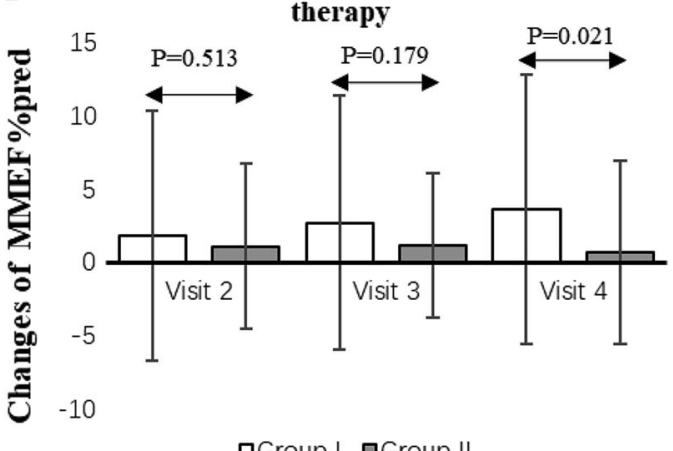

口Group | 口Group ||

therapy; Visit 4: at the end of 6 months of therapy. $C A T$ COPD assessment test, $M E F_{50} \%$ pred forced expiratory flow after $50 \%$ of the $\mathrm{FVC} \%$ predicted, $M E F_{25} \%$ pred forced expiratory flow after $25 \%$ of the FVC\% predicted, $M M E F \%$ pred maximal mid expiratory flow\% predicted

Table 4 The improvement of mMRC were compared between in two groups during follow-up

\begin{tabular}{|c|c|c|c|c|c|}
\hline \multirow[t]{2}{*}{ Follow-up } & \multicolumn{2}{|l|}{ Group I } & \multicolumn{2}{|l|}{ Group II } & \multirow[t]{2}{*}{$p$ value } \\
\hline & Relieved (\%) & Not relieved (\%) & Relieved (\%) & Not relieved (\%) & \\
\hline Visit $2(n=164)$ & $42(51.22)$ & $40(48.78)$ & $35(42.68)$ & $47(57.32)$ & 0.049 \\
\hline Visit $3(n=155)$ & $51(65.38)$ & $27(34.62)$ & $52(67.53)$ & $25(32.47)$ & 0.926 \\
\hline Visit $4(n=142)$ & $61(85.92)$ & $10(34.62)$ & $57(80.28)$ & $14(19.72)$ & 0.926 \\
\hline
\end{tabular}

Group I: tiotropium $18 \mu \mathrm{g}$ once-daily + theophylline $100 \mathrm{mg}$ twice-daily groups; Group II: tiotropium $18 \mu \mathrm{g}$ once-daily group; Visit 2: at the end of 1 month of herapy; Visit 3: at the end of 3 months of therapy; Visit 4: at the end of 6 months of therapy

$m M R C$ modified Medical Research Council

\section{CONCLUSION}

To conclude, the combination of tiotropium and low-dose theophylline significantly improved the symptoms and general health of stable COPD patients of groups B and D after 6 months of treatment. In the short period of 1 month, the combination therapy was more 
Table 5 Adverse events of two therapy groups

\begin{tabular}{llll}
\hline & Group I & Group II & $\boldsymbol{p}$ value \\
\hline$n$ & 85 & 85 & \\
Total (\%) & $26(30.59)$ & $23(27.06)$ & 0.611 \\
Serious adverse events & $4(4.71)$ & $5(5.88)$ & 0.732 \\
Death & 0 & 0 & \\
Hospitalization & $4(4.71)$ & $5(5.88)$ & 0.732 \\
AECOPD hospitalization & $3(3.53)$ & $4(4.71)$ & 0.700 \\
Non-AECOPD hospitalization & $1(1.18)$ & $1(1.18)$ & 1.000 \\
AECOPD & $7(8.24)$ & $6(7.06)$ & 0.773 \\
Dry mouth & $13(15.29)$ & $16(18.82)$ & 0.541 \\
Dry eyes & $3(3.53)$ & $1(1.18)$ & 0.312 \\
Palpitation & $1(1.18)$ & 0 & 0.316 \\
Nausea & $1(1.18)$ & 0 & 0.316 \\
Rash & $1(1.18)$ & 0 & 0.316 \\
\hline
\end{tabular}

Group I: tiotropium $18 \mu \mathrm{g}$ once-daily + theophylline $100 \mathrm{mg}$ twice-daily groups; Group II: tiotropium $18 \mu \mathrm{g}$ once-daily group

$A E C O P D$ acute exacerbation of chronic obstructive pulmonary disease

rapid in significantly relieving symptoms than the monotherapy; therefore, a combination regimen can be considered to relieve symptoms at initial treatment of COPD patients with severe symptoms. Low-dose theophylline (200 mg/day) in combination with tiotropium improved the indicators of small airway function in patients with stable COPD of groups B and $\mathrm{D}$. The specific mechanism of improvement needs further basic research.

\section{ACKNOWLEDGEMENTS}

We sincerely thank all the patients who participated in this study.

Funding. This study was partially funded by Science and technology support project of Sichuan province (2015SZ0234-3). The article Processing charges and the Open Access Fee were funded by the authors.
Authorship. All named authors meet the International Committee of Medical Journal Editors (ICMJE) criteria for authorship for this article, take responsibility for the integrity of the work as a whole, and have given their approval for this version to be published.

Disclosures. Xiao-feng Xiong, Li-li Fan, Hong-xia Wu, Min Zhu, De-yun Cheng have nothing to disclose.

Compliance with Ethics Guidelines. The study was approved by the institutional ethics committees of West China Hospital of Sichuan University, and it has been registered in the China Clinical Trials Registry on October 21, 2018 (ChiCTR1800019027). All participants gave informed consent, and all work was conducted in accordance with the Declaration of Helsinki (1964).

Data Availability. The data sets generated during and/or analyzed during the current 
study are available from the corresponding author on reasonable request.

Open Access. This article is distributed under the terms of the Creative Commons Attribution-NonCommercial 4.0 International License (http://creativecommons.org/licenses/ by-nc/4.0/), which permits any noncommercial use, distribution, and reproduction in any medium, provided you give appropriate credit to the original author(s) and the source, provide a link to the Creative Commons license, and indicate if changes were made.

\section{REFERENCES}

1. Global initiative for chronic obstructive lung disease. Global strategy for the diagnosis, management, and prevention of chronic obstructive pulmonary disease 2017 report [EB/OL](2016-1116). http://www.goldcopd.org. Accessed 3 Jan 2017.

2. Mathers CD, Loncar D. Projections of global mortality and burden of disease from 2002 to 2030 . PLoS Med. 2006;3(11):e442. https://doi.org/10. 1371/journal.pmed.0030442.

3. Global strategy for the diagnosis, management, and prevention of COPD (revised 2011) [EB/OL] (201111). http://www.goldcopd.org. Accessed 2 Jan 2011.

4. Vestbo J, Vogelmeier C, Small M, Higgins V. Understanding the GOLD 2011 strategy as applied to a real-world COPD population. Resp Med. 2014;108(5):729-36. https://doi.org/10.1016/j. rmed.2014.03.002.

5. Jones PW, Nadeau G, Small M, Adamek L. Characteristics of a COPD population categorised using the GOLD framework by health status and exacerbations. Resp Med. 2014;108(1):129-35. https://doi. org/10.1016/j.rmed.2013.08.015.

6. Han MLK, Muellerova H, Curran-Everett D, Dransfield MT, Washko GR, Regan EA, Bowler RP, Beaty TH, Hokanson JE, Lynch DA, Jones PW, Anzueto A, Martinez FJ, Crapo JD, Silverman EK, Make BJ. GOLD 2011 disease severity classification in COPDGene: a prospective cohort study. Lancet Resp Med. 2013;1(1):43-50. https://doi.org/10. 1016/S2213-2600(12)70044-9.

7. Soriano JB, Alfageme I, Almagro P, Casanova C, Esteban C, Soler-Cataluna JJ, de Torres JP, MartinezCamblor P, Miravitlles M, Celli BR, Marin JM. Distribution and prognostic validity of the New
Global Initiative for Chronic Obstructive Lung Disease grading classification. Chest. 2013;143(3):694-702. https://doi.org/10.1378/ chest.12-1053.

8. Tashkin DP, Celli B, Senn S, Burkhart D, Kesten S, Menjoge S, Decramer M, Investigators US. A 4-year trial of tiotropium in chronic obstructive pulmonary disease. $\mathrm{N}$ Engl J Med. 2008;359(15):1543-54. https://doi.org/10.1056/ NEJMoa0805800.

9. Wedzicha JA, Calverley PM, Seemungal TA, Hagan G, Ansari Z, Stockley RA, Investigators I. The prevention of chronic obstructive pulmonary disease exacerbations by salmeterol/fluticasone propionate or tiotropium bromide. Am J Respir Crit Care Med. 2008;177(1):19-26. https://doi.org/10.1164/rccm. 200707-973OC.

10. Decramer M, Celli B, Kesten S, Lystig T, Mehra S, Tashkin DP, Investigators U. Effect of tiotropium on outcomes in patients with moderate chronic obstructive pulmonary disease (UPLIFT): a prespecified subgroup analysis of a randomised controlled trial. Lancet. 2009;374(9696):1171-8. https://doi.org/10.1016/S0140-6736(09)61298-8.

11. Kanehara M, Yokoyama A, Tomoda Y, Shiota N, Iwamoto H, Ishikawa N, Taooka Y, Haruta Y, Hattori N, Kohno N. Anti-inflammatory effects and clinical efficacy of theophylline and tulobuterol in mild-to-moderate chronic obstructive pulmonary disease. Pulm Pharmacol Ther. 2008;21(6):874-8. https://doi.org/10.1016/j.pupt.2008.09.003.

12. Berger R, Smith D. Acute postbronchodilator changes in pulmonary function parameters in patients with chronic airways obstruction. Chest. 1988;93(3):541-6.

13. Global strategy for the diagnosis, management, and prevention of COPD, update January 2015 [EB/OL]. http://www.goldcopd.org. Accessed 3 Jan 2015.

14. Jones PW, Beeh KM, Chapman KR, Decramer M, Mahler DA, Wedzicha JA. Minimal clinically important differences in pharmacological trials. Am J Respir Crit Care Med. 2014;189(3):250-5. https:// doi.org/10.1164/rccm.201310-1863PP.

15. Celli B, Decramer M, Kesten S, Liu D, Mehra S, Tashkin DP, Investigators US. Mortality in the 4-year trial of tiotropium (UPLIFT) in patients with chronic obstructive pulmonary disease. Am J Respir Crit Care Med. 2009;180(10):948-55. https://doi. org/10.1164/rccm.200906-0876OC.

16. Sampablo I, Carone M, Antoniu SA. Tiotropium therapy and mortality risk in COPD patients: the most severe, the most protected? Evaluation of Celli B, Decramer M, Kesten S, et al. Mortality in the 
4-year trial of tiotropium (UPLIFT) in patients with chronic obstructive pulmonary disease. Am J Respir Crit Care Med 2009; 180(10): 948-55. Expert Opin Pharmacother. 2010;11(8):1439-41. https://doi. org/10.1517/14656561003745916.

17. Vogelmeier C, Hederer B, Glaab T, Schmidt $H$, Rutten-van Molken MP, Beeh KM, Rabe KF, Fabbri LM, Investigators P-C. Tiotropium versus salmeterol for the prevention of exacerbations of COPD. N Engl J Med. 2011;364(12):1093-103. https://doi. org/10.1056/NEJMoa1008378.

18. Chong J, Karner C, Poole P. Tiotropium versus longacting beta-agonists for stable chronic obstructive pulmonary disease. Cochrane Database Syst Rev. 2012;9:CD009157. 14651858.cd009157.pub2.

19. Suissa S, Dell'Aniello S, Ernst P. Long-acting bronchodilator initiation in COPD and the risk of adverse cardiopulmonary events a populationbased comparative safety study. Chest. 2017;151(1):60-7. https://doi.org/10.1016/j.chest. 2016.08.001.

20. Kawayama $T$, Hoshino $T$, Ichiki $M$, Tsuda $T$, Kinoshita M, Takata S, Koga T, Iwanaga T, Aizawa H, Kurume CSG. Effect of add-on therapy of tiotropium in COPD treated with theophylline. Int J Chronic Obstr Pulm Dis. 2008;3(1):137-47.

21. Kohansal R, Martinez-Camblor P, Agusti A, Buist AS, Mannino DM, Soriano JB. The natural history of chronic airflow obstruction revisited: an analysis of the Framingham offspring cohort. Am J Respir Crit Care Med. 2009;180(1):3-10. https://doi.org/10. 1164/rccm.200901-0047OC.
22. Hogg JC, Timens W. The pathology of chronic obstructive pulmonary disease. Annu Rev Pathol. 2009;4:435-59. https://doi.org/10.1146/annurev. pathol.4.110807.092145.

23. Chrystyn H, Mulley BA, Peake MD. Dose response relation to oral theophylline in severe chronic obstructive airways disease. BMJ. 1988;297(6662):1506-10.

24. Kidney J, Dominguez M, Taylor PM, Rose M, Chung $\mathrm{KF}$, Barnes PJ. Immunomodulation by theophylline in asthma. Demonstration by withdrawal of therapy. Am J Respir Crit Care Med. 1995;151(6):1907-14. https://doi.org/10.1164/ ajrccm.151.6.7767539.

25. Barnes PJ. Theophylline. Am J Respir Crit Care Med. 2013;188(8):901-6. https://doi.org/10.1164/rccm. 201302-0388PP

26. Tsukagoshi H, Shimizu Y, Iwamae S, Hisada T, Ishizuka T, Iizuka K, Dobashi K, Mori M. Evidence of oxidative stress in asthma and COPD: potential inhibitory effect of theophylline. Respir Med. 2000;94(6):584-8. https://doi.org/10.1053/rmed.2000.0785.

27. Culpitt SV, de Matos C, Russell RE, Donnelly LE, Rogers DF, Barnes PJ. Effect of theophylline on induced sputum inflammatory indices and neutrophil chemotaxis in chronic obstructive pulmonary disease. Am J Respir Crit Care Med. 2002;165(10):1371-6.

28. Kesten S, Jara M, Wentworth C, Lanes S. Pooled clinical trial analysis of tiotropium safety. Chest. 2006;130(6):1695-703. https://doi.org/10.1378/ chest.130.6.1695. 